\title{
Mengenal Tanda-Tanda Bahaya Kehamilan di Puskesmas Pakuan Baru Kota Jambi
}

\author{
Ria Febrina \\ Program Studi D III Kebidanan STIKes Baiturrahim Jambi \\ Email: febrinaria2002@gmail.com
}

Submitted : 26/11/2020

Accepted:10/12/2020

Published: 11/01/2021

\begin{abstract}
Maternal Mortality Rate (MMR) in Indonesia is still high compared to other ASEAN countries. MMR in Indonesia according to the 2017 Indonesian Demographic and Health Survey (IDHS) is 305 per 100,000 live births. The global target of SDGs (Suitainable Development Goals) is to reduce the Maternal Mortality Rate (MMR) to 70 per 100,000 live births. While in Jambi Province in 2017 recorded maternal deaths were 29 cases. Maternal deaths that occur during $90 \%$ of pregnancy are caused by obstetric complications. Direct obstetric complications are bleeding, infection and eclampsia. Indirectly maternal mortality is also influenced by delays at the family level in recognizing danger signs of pregnancy and making decisions to immediately seek help. Delay in reaching health facilities and assistance in health service facilities. Pregnancy danger signs must be recognized and detected early so that they can be handled properly because any danger signs of pregnancy can lead to pregnancy complications. Therefore it is necessary to provide counseling to improve the knowledge of pregnant women about the danger signs of pregnancy. This community service activity was carried out by Pakuan Baru Kota Jambi Public Health Center. The time of implementation in April 2020. The target is pregnant women. Community service methods include a survey and lecture approach. The results obtained are pregnant women able to understand the danger signs of pregnancy. It is recommended for health workers to continue to provide education related to pregnancy to pregnant women
\end{abstract}

Keywords : pregnancy, pregnant woman, signs of pregnancy danger

\begin{abstract}
Abstrak
Angka Kematian Ibu (AKI) di Indonesia masih tinggi dibandingkan dengan negara ASEAN lainnya. AKI di Indonesia menurut Survei Demografi dan Kesehatan Indonesia (SDKI) tahun 2017 sebesar 305 per 100.000 kelahiran hidup. Target global SDGs (Suitainable Development Goals) adalah menurunkan Angka Kematian Ibu (AKI) menjadi 70 per 100.000 Kelahiran hidup. Sementara di Propinsi Jambi pada tahun 2017 tercatat kematian ibu sebanyak 29 kasus. Kematian ibu yang terjadi pada waktu kehamilan 90\% disebabkan oleh komplikasi obstetric. Komplikasi obstetri secara langsung adalah Perdarahan, infeksi dan eklamsia. Secara tidak langsung kematian ibu juga dipengaruhi oleh keterlambatan ditingkat keluarga dalam mengenali tanda bahaya kehamilan dan membuat keputusan untuk segera mencari pertolongan. Keterlambatan dalam mencapai fasilitas kesehatan dan pertolongan difasilitas pelayanan kesehatan. Tanda bahaya kehamilan harus dikenali dan terdeteksi sejak dini sehingga dapat ditangani dengan benar karena setiap tanda bahaya kehamilan bisa mengakibatkan komplikasi kehamilan. Maka dari itu diperlukan memberikan penyuluhan untuk meningkatkan pengetahuan ibu hamil mengenai tanda-tanda bahaya kehamilan. Kegiatan pengabdian masyarakat ini dilaksanakan Puskesmas Pakuan Baru Kta Jambi. Waktu pelaksanaan pada bulan April 2020. Sasaran adalah ibu hamil. Metode pengabdian masyarakat meliputi pendekatan survey dan ceramah. Hasil yang diperoleh adalah ibu hamil mampu memahami mengenai tanda-tanda bahaya kehamilan. Disarankan kepada tenaga kesehatan untuk tetap mempertahankan pemberian edukasi terkait kehamilan pada ibu hamil.
\end{abstract}

Kata Kunci : ibu hamil, kehamilan, tanda bahaya kehamilan 


\section{PENDAHULUAN}

Angka Kematian Ibu (AKI) merupakan salah satu indikator penting dalam menilai derajat kesehatan masyarakat. Kematian Ibu dapat digunakan dalam pemantauan kematian terkait dengan kehamilan. Indikator ini dipengaruhi status kesehatan secara umum, pendidikan dan pelayanan selama kehamilan dan melahirkan. Sensitifitas AKI terhadap perbaikan pelayanan kesehatan menjadikannya indikator keberhasilan pembangunan sector kesehatan.

Berdasarkan data dari World Health Organization (WHO) tahun 2014 melaporkan AKI dunia yaitu 289.000 jiwa. Amerika Serikat yaitu 9.300 jiwa, Afrika Utara 179.000 jiwa, dan Asia Tenggara 16.000 jiwa. AKI di negara-negara Asia Tenggara yaitu Indonesia 214 per 100.000 kelahiran hidup, Filiphina 170 per 100.000 kelahiran hidup, Vietnam 160 per 100.000 kelahiran hidup, Thailand 44 per 100.000 kelahiran hidup, Brunei 60 per 100.000 kelahiran hidup, dan Malaysia 39 per 100.000 kelahiran hidup. Indonesia AKI mencapai 305 per 100.000 kelahiran hidup dengan jumlah kasus sebesar 14.623 kasus. Sedangkan AKB di Indonesia tercatat 24 per 100.000 kelahiran hidup dengan jumlah kasus dasar 151.200 kasus. Hasil laporan dari Bidang Kesehatan Masyarakat terhadap jumlah Kematian ibu (hamil, bersalin, an nifas) di Provinsi Jambi tahun 2017 adalah 54 kasus dengan jumlah kelahiran hidup sebanyak 68.886 kelahiran hidup. Jika diproyeksikan angka kematian ibu diprovinsi jambi tahun 2017 adalah 78 per 100.000 kelahiran hidup.

Kematian ibu menggambarkan jumlah wanita yang meninggal dari suatu penyebab kematian terkait dengan gangguan kehamilan atau penanganannya (tidak termasuk kecelakaan atau kasus insidentil) selama kehamilan, melahirkan dan dalam masa nifas (42 hari setelah melahirkan) tanpa memperhitungkan lama kehamilan. Adapun Penyebab kematian ibu adalah komplikasi kehamilan seperti anemia, hipertensi dan eklamsi yang merupakan tanda bahaya kehamilan.

Pengawasan sebelum lahir (antenatal) terbukti mempunyai kedudukan yang sangat penting dalam upaya meningkatkan kesehatan mental dan fisik, untuk menghadapi persalinan. Dengan pengawasan hamil dapat diketahui berbagai komplikasi ibu yang dapat mempengaruhi kehamilan atau komplikasi hamil sehingga dapat segera diatasi. Yang tidak mungkin dapat diatasi segera dirujuk ke tempat yang lebih lengkap peralatannya sehingga mendapat perawatan yang optimal.

Pengawasan pada saat hamil dapat menurunkan Angka Kematian Ibu (AKI) maupun Angka Kematian Bayi (AKB). Sebagai cermin kemampuan setiap bangsa untuk memberikan pelayanan dan pengayoman medis terhadap masyarakatnya (Siti Bandiyah, 2009).

Fenomena angka kematian ibu yang masih tergolong tinggi tersebut salah satunya dapat dipengaruhi oleh pendidikan ibu hamil yang nantinya juga berpengaruh terhadap pengetahuan ibu hamil tentang tanda bahaya kehamilan. Pendidikan adalah suatu proses belajar yang berarti dalam pendidikan itu terjadi proses pertumbuhan, perkembangan, atau perubahan kearah yang lebih dewasa. Pengetahuan

merupakan domain yang sangat penting untuk terbentuknya tindakan seseorang. Pengetahuan sangat erat hubungannya dengan pendidikan dimana seseorang dengan pendidikan tinggi, maka orang tersebut akan semakin luas pengetahuannya (Notoatmodjo, 2007). Dalam hal ini ibu hamil yang berpendidikan tinggi akan mempunyai pengetahuan lebih luas mengenai tanda bahaya kehamilan.

Deteksi dini tanda bahaya kehamilan sangat diperlukan sebagai salah satu upaya dalam menurunkan AKI. Penatalaksanaan deteksi dini dapat dilakukan sesuai dengan 
standar kompetensi bidan Nomor 369/MENKES/SK/III/2007 kompetensi ke2 yaitu melakukan pemeriksaan kehamilan secara rutin pada tenaga kesehatan paling sedikit 4 kali selama kehamilannya yaitu 1 kali pada trimester I, 1 kali pada trimester II, dan 2 kali pada trimester III. Pada standar Ante Natal Care (ANC) terdiri dari $14 \mathrm{~T}$, dimana penyuluhan pada ibu hamil masuk pada urutan ke-13 yatu tingkatkan pengetahuan ibu hamil (penyuluhan) seperti, makanan bergizi ibu hamil, tanda bahaya kehamilan, petunjuk agar tidak terjadi bahaya pada waktu kehamilan dan persalinan. Menurut KepMenkes nomor 928 tahun 2007 tentang standar asuhan kebidanan bahwa asuhan kebidanan dilakukan berdasarkan buku KIA yang salah satu isinya menjelaskan tentang tanda bahaya kehamilan (Kemenkes, RI, 2014).

Penelitian yang dilakukan oleh Mursidah (2011) menunjukkan bahwa pada saat pre test kelompok perlakuan memperoleh tingkat pengetahuan baik sebesar $(40 \%)$ responden, cukup (30\%) responden, kurang (30\%) responden. Setelah diberikan penyuluhan tentang tanda bahaya kehamilan pada kelompok perlakuan atau pada saat post test memperoleh tingkat pengetahuan baik sebesar $(83,3 \%)$ responden, cukup $(10 \%)$ responden, dan kurang $(6,67 \%)$ responden.

Berdasarkan alasan diatas maka ibu hamil perlu mendapatkan edukasi mengenai tanda-tanda kehamilan sebagai upaya deteksi dini kemungkinan adanya resiko tinggi atau komplikasi pada masa kehamilan atau persalinan.

\section{TARGET DAN LUARAN}

1. Target

Target dalam kegiatan pengabdian kepada masyarakat ini adalah ibu hamil

2. Luaran

Adapun luaran kegiatan pengabdian masyarakat ini selain publikasi pada jurnal ilmiah yaitu: a. Pemahaman dan peningkatan pengetahuan ibu hamil tentang tanda-tanda bahaya kehamilan

b. Serta sebagai salah satu upaya deteksi dini adanya resiko tinggi atau komplikasi dalam kehamilan.

\section{METODE PELAKSANAAN}

Kegiatan pengabdian kepada masyarakat dilaksanakan pada bulan Juli 2019 dengan sasaran kegiatan adalah ibu hamil berjumlah 10 orang.

Tahapan kegiatan pengabdian kepada masyarakat meliputi:

Persiapan

1. Sosialisasi: pertemuan dengan pihak puskemas Pakuan Baru.

2. Mengidentifikasi masalah.

3. Permusuan solusi : menyampaikan rencana kegiatan kepada pihak Puskesmas dengan mengurus surat izin melakukan kegiatan pengabdian kepada masyarakat.

Pelaksanaan

1. Melakukan pretest (menggali pemahaman ibu hamil tentang tanda bahaya kehamilan)

2. Memberikan pendidikan kesehatan dengan cara konseling tentang tandatanda bahaya kehamilan. Materi yang diberikan adalah mulai dari pengertian, macam tanda bahaya kehamilan, komplikasi yang ditimbulkan dan cara mencegah terjadinya bahaya dalam kehamilan.

3. Media yang digunakan dalam pengabdian ini adalah penggunaan leaflet.

4. Metode diskusi dan tanya jawab

\section{HASIL DAN PEMBAHASAN}

Kegiatan penyuluhan ini bertujuan agar ibu hamil memahami tentang tandatanda bahaya kehamilan. Pada pengabdian ini dilakukan pendidikan kesehatan kepada ibu hamil mengenai tanda-tanda bahaya kehamilan. Kegiatan penyuluhan berlangsung kurang lebih 30 menit dan 
terlaksana dengan tertib dan lancar serta mendapat antusias yang baik dari para peserta dan pihak Puskesmas. Kegiatan yang dilakukan adalah memberikan edukasi kesehatan berupa penyuluhan yang meliputi pengertian tanda-tanda bahaya kehamilan, macam tanda bahaya kehamilan, komplikasi yang ditimbulkan dan cara mencegah terjadinya bahaya dalam kehamilan.

Upaya penurunan kematian ibu dan bayi dapat dilakukan dengan peningkatan kualitas pelayanan kesehatan ibu dan anak (Depkes, 2010), untuk itu sangat penting sekali bagi ibu hamil mengetahui tentang tanda-tanda bahaya kehamilan.

Pendidikan kesehatan merupakan suatu proses untuk menyadarkan, meningkatkan pengetahuan dan merubah perilaku masyarakat tentang kesehatan. Pendidikan kesehatan bertujuan agar masyarakat menyadari dan mengetahui cara memelihara kesehatan, menghindari atau mencegah dari hal-hal yang merugikan kesehatan serta bagaimana mencari pengobatan yang tepat (Notoatmojo, 2007).

Pemberian penyuluhan diharapkan dapat meningkatkan pengetahuan ibu hamil tentang tanda-tanda bahaya kehamilan dan pentingnya ibu menjaga dirinya agar tetap sehat pada masa kehamilan serta meningkatkan kesadaran ibu tentang kemungkinan adanya resiko tinggi atau terjadinya komplikasi kehamilan, persalinan dan nifas.

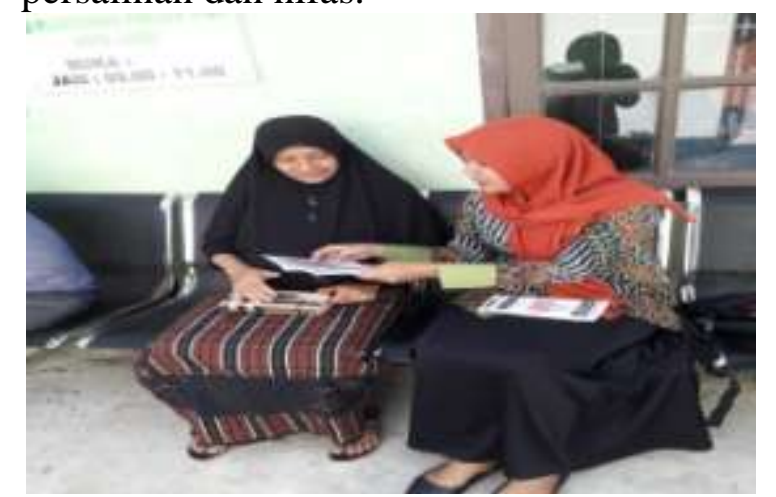

Gambar 1. Penyuluhan kesehatan

Umumnya 80-90 \% kehamilan berlangsung dengan normal dan hanya 10-
$20 \%$ kehamilan yang disertai dengan penyulit atau berkembang menjadi patologis. Kehamilan patologis sendiri tidak terjadi secara mendadak karena kehamilan dan efeknya terhadap organ tubuh berlangsung secara bertahap dan berangsurangsur. Deteksi dini gejala dan tanda bahaya selama kehamilan merupakan upaya terbaik untuk mencegah terjadinya gangguan yang serius terhadap kehamilan ataupun keselamatan ibu hamil (Prawirohardjo, 2011).

Deteksi dini gejala dan tanda bahaya kehamilan dapat dilakukan dengan upaya memberikan pendidikan kesehatan melalui penyuluhan kepada ibu hamil, sehingga ibu hamil siap dan mengerti perubahan yang terjadi pada dirinya. Hal ini sejalan dengan hasil penelitian ni nyoman, dkk (2017) ada pengaruh penyuluhan tanda bahaya kehamilan terhadap peningkatan pengetahuan pada ibu hamil.

Hasil penelitian tersebut didukung teori yang dikemukakan oleh Notoatmodjo (2011), bahwa pengetahuan menjadi landasan penting untuk menentukan suatu tindakan. Orang yang berpengetahuan baik akan mengupayakan kemampuan menerapkan pengetahuannya didalam kehidupan sehari-hari. Pengetahuan atau kognitifmerupakan domain yang sangat penting untuk terbentuknya suatu tindakan seseorang (overt behavior). Dari pengalaman dan penelitian ternyata perilaku yang dasari oleh pengetahuan akan lebih langgeng dari pada perilaku yang tidak didasari oleh pengetahuan.

Salah satu upaya untuk dapat mengenali tanda bahaya kehamilan adalah dengan pemanfaatan buku KIA. Pengadaan buku KIA merupakan upaya pemerintah yang sudah tersosialisasi sejak tahun 2014 sampai sekarang. Dengan adanya buku KIA diharapkan dapat meningkatkan pengetahuan tentang kehamilan dan persalinan khususnya deteksi dini tanda bahaya kehamilan. Hal ini sejalan dengan hasil penelitian Ode Iis (2015) menyatakan 
bahwa pemberian penyuluhan tentang pemanfaatan buku KIA berpengaruh terhadap sikap deteksi dini tanda bahaya kehamilan pada ibu hamil.

\section{KESIMPULAN DAN SARAN}

\section{Kesimpulan}

Pelaksanaan pengabdian kepada masyarakat khusunya ibu hamil di Puskesmas Pakuan Baru Kota Jambi yang dilakukan oleh dosen Sekolah Tinggi Ilmu Kesehatan Baiturrahim Jambi berjalan dengan baik. Ibu hamil dapat memahami tentang tanda-tanda bahaya kehamilan

\section{Saran}

Diharapkan pihak puskesmas Pakuan Baru dapat secara rutin memberikan pendidikan kesehatan terkait kesehatan mulai dari kehamilan sampai masa nifas serta dapat melakukan evaluasi dari penyuluhanpenyuluhan yang sudah diberikan untuk memantau tingkat pemahamam ibu hamil terkait informasi yang telah didapatkan.

\section{UCAPAN TERIMAKASIH}

Ucapan terimakasih kami sampaikan kepada Sekolah Tinggi Ilmu Kesehatan Baiturrahim Jambi yang telah memfasilitasi kegiatan ini, dan tak lupa kepada semua pihak yang telah membantu kegiatan kepada masyarakat ini.

\section{DAFTAR PUSTAKA}

Depkes. 2010. Pedoman Pelayanan natenatal Terpadu. Depkes: Jakarta.

Kementrian Kesehatan RI. 2018. Riset Kesehatan Dasar 2018. Badan Penelitian dan Pengembangan Kesehatan Kementrian Kesehatan RI.
Kemenkes RI.2014. Peraturan Menteri Kesehatan RI Nomor 97 tahun 2014 Tentang Pelayanan Kesehatan Masa Sebelum Hamil, Masa Hamil, Persalinan, Dan Masa Sesudah Melahirkan, Penyelenggaraan Pelayanan Kontrasepsi, Serta Pelayanan Kesehatan Seksual. Jakarta

Mursida S, Widya NE. 2011. Perbedaan tingkat pengetahuan ibu promigravida sebelum dan setelah dilakukan penyuluhan tentang tanda bahaya kehamilan di PKD Mekar Sari Desa Ngargotirto Sumber Lawang Sragen. Jurnal Kebidanan. Juni; Volume 3(1): 15-20.

Ni Nyoman, dkk. 2017. Efektivitas Penyuluhan Tanda Bahaya Kehamilan Terhadap Peningkatan Pengetahuan pad Ibu Hamil di Desa Pasirmulya Kabupaten Bandung Tahun 2015. Jurnal Reproductive Health. 22/12 (2017), 78-83.

Notoatmodjo. 2011. Promosi Kesehatan dan Ilmu Perilaku. Rineka Cipta: Jakarta.

Ode Iis, SN. 2015. Pengaruh Penyuluhan Pemanfaatan Buku KIA terhadap Sikap Deteksi Dini Tanda Bahaya Kehamilan pada Ibu Hamil di Kelurahan Bangunharjo Sewon Bantul. STIKes Aisyiyah Yogyakarta.

Saifudin, Abdul B. 2002. Buku Panduan Praktis Pelayanan Kesehatan Maternal \& Neonatal. Yayasan Bina Pustaka : Jakarta

Winkjosastro, H. 2007. Ilmu Kebidanan.

Yayasan Bina Pustaka Sarwono Prawirohardjo : Jakarta. 